\title{
ASSESSMENT OF TRAUMATIC DENTAL INJURIES OF PERMANENT INCISORS IN A GROUP OF VISUALLY IMPAIRED EGYPTIAN CHILDREN AND ITS ASSOCIATION WITH INFLUENCING FACTORS
}

\author{
Adel Abdel Azeem ElBardissy*
}

\begin{abstract}
Background: prevalence of traumatic dental injuries (TDIs) among visually impaired children varies from one country to another. Different factors aside visual impairment influences the prevalence as well as the severity of such injuries. Evaluating the level of the health care provided for those children by comparing number of traumatized cases and number of treated cases would help in documenting the need for creating a special health care program for them. Aim: this study aims at assessment of traumatic dental injuries in a group of visually impaired Egyptian children and the effect of the relative factors in their prevalence.
\end{abstract}

Design: A cross sectional analytic study using a questionnaire and clinical examination was conducted to assess the prevalence of TDIs of the upper and lower permanent incisors and its relevant factors in children attending two governmental schools for blind children, one school for girls and the other one for boys.

Results: Among 402 blind students examined in the current study, 210 (52.2\%) students were males and $192(47.8 \%)$ were females. Prevalence of traumatic dental injuries among the study population was $9.95 \%$ (40 students). Prevalence of traumatic dental injuries among males was $(11.43 \%)$ while it was $(8.33 \%)$ among females, the difference was not significant. Upper central incisors had the highest frequency of trauma $(72.5 \%)$ and fracture of enamel and dentine was the most frequent TDIS (57.5\%). Fall was the most common cause of injury (55\%) and the most frequent place of injury was at home $(55 \%)$. Mean age of children at time of injury is $11.85( \pm 1.47)$ years. Only five cases (12.5\%) had dental treatment and restoration of their traumatic injuries. There were significant correlations between increased overjet and/ or inadequate lip coverage and the prevalence of TDIs.

Conclusions: Environmental factors proposed to influence the prevalence of TDIs were difficult to evaluate in the presence of similar conditions in both schools. The most significant oral factors in predisposing TDIs in blind children are increased overjet and inadequate lip coverage. More efforts are needed to provide better dental health care service for visually impaired children.

KEYWORDS: Dental trauma - Visually impaired children - Predisposing Factors.

*Associate Professor of Pediatric Dentistry, Cairo University 


\section{INTRODUCTION}

Risk factors of traumatic dental injuries (TDIs) comprise oral factors, environmental factors and human behavior ${ }^{(1)}$.

Oral predisposing factors embrace increased overjet, inadequate lip coverage ${ }^{(2-5)}$, anterior open bite, position of the teeth, rigidity of the maxilla versus flexibility of the lower jaw and malocclusion traits. ${ }^{(6)}$.

Environmental factors are typically associated with material deficiency; this is usually associated with overcrowding and presence of unsafe playgrounds at schools in deprived communities, and adverse psychological environments and socioeconomic status ${ }^{(6,7}$, and 8$)$.

TDIs results from falls, crashes and being hit by an object. What make some vulnerable persons more susceptible to TDIs are environmental factors as material deprivation as well as human behavior such as: Risk-taking children ${ }^{(9)}$, emotional stressful conditions ${ }^{(10)}$, and obesity ${ }^{(11)}$.

Prevalence of TDIs in children with special health care needs varied according to the type of handicapping problem. Children suffering from attention-deficit hyperactivity disorder (12), learning disabilities (13) and hearing or visual impairment ${ }^{(14)}$ have higher prevalence of TDIs than in healthy populations.

The 11th revision of the WHO International Statistical Classification of Diseases, Injuries and Causes of Death, defined Low Vision visual acuity of less than $6 / 18$ but equal to or better than $3 / 60$, or corresponding visual field loss to less than $20^{\circ}$, in the better eye with the best possible correction. "Blindness" is defined as visual acuity of less than $3 / 60$, or corresponding visual field loss to less than $10^{\circ}$, in the better eye with the best possible correction. "Visual Impairment" includes both low vision and blindness ${ }^{(15)}$.

Blind children move and play as healthy children, however, they are more liable to misfortunes, such as crashes and falls, in contrast to seeing children hence, they experience more mental traumas ${ }^{(16)}$.

The World Health Organization Stated That blindness institutes a public health problem when countrywide blindness rate is $0.5 \%$ or greater ${ }^{(17)}$.

A community blindness rate of $1 \%$ or greater signifies that blindness is a public health problem.

In Egypt a crude blindness rate of $2.1 \%$ was estimated in a study in Alexandria Governorate ${ }^{(18)}$.

Blindness rates were expected to increase in Egypt from approximately $1.6 \%$ to $2.2 \%$ in the year 2000 to be $3.1 \%$ in the year $2020^{(19)}$.A study on the prevalence of visual impairment and blindness in Upper Egypt revealed a rate of $23.9 \%$ of best eye presenting visual impairment,6.4\% with severe visual impairment and $9.3 \%$ of blindness ${ }^{(20)}$.

The prevalence of traumatic dental injury of permanent anterior teeth in visually impaired children is ranging worldwide from $4.1 \%$ to $58.6 \%{ }^{(21)}$.

Prevalence of traumatic injuries of the permanent teeth in 80 visually impaired children was $35 \%$ compared to $4 \%$ in matched number of sighted children in Iran ${ }^{(16)}$

In India nearly the same prevalence 34.95 $\%$ were found among 103 blind individuals (22) while it was $35.7 \%$ among 80 visually impaired children in another study ${ }^{(23)}$ with Increased overjet and inadequate lip coverage being significantly associated with the occurrence of trauma in both studies.

Another Indian study performed over a larger visually impaired children population (400) reveals a 39\% prevalence of TDIs where most of the TDIs were at home most often because of fall or crashes ${ }^{(24)}$.

Prevalence of TDIs in visually impaired population in Sudan was found close to the previously mentioned percentages in other countries where it was $32.6 \%$ among 141 visually impaired individual 
in a study in two institutes in Khartoum North ${ }^{(25)}$.

The current study aims at assessment of traumatic dental injuries in a group of visually impaired Egyptian children and the effect of the relative factors in their prevalence.

According to the education administration department there were 3000 blind students distributed over 30 schools all over Egypt.

\section{MATERIALS AND METHODS}

This study conducted using a questionnaire and clinical examinations to assess the prevalence of TDIs of the upper and lower permanent incisors and its relevant factors in four hundred and two children, who accepted to be included in the study, attending two governmental schools for blind children, one school for girls and the other one for boys.

This study was approved by the Research Ethical Committee, Faculty of Dentistry, Cairo University. A letter from the faculty was introduced to the educational administrations responsible for these schools. Nature of the study was explained to the school authorities.

The researcher offered an arrangement for dental treatment for any child at both schools at the Dental Unit of Children with Special Health Care Needs at the Faculty of Dentistry, Cairo University.

Written permissions were signed by the parents / guardians of the children to be included in the dental examination and the study.

Both schools have children in the different grads starting from kindergarten level to high school level. Boys' school is a boarding school while the school for girls is a non-boarding school.

Visually impaired children with the following Inclusion criteria were included in the current study:

1- Apparently healthy children rather than blindness.
2- Childrn had trauma to their teeth either treated or not treated.

3- Children aged 10-17 years.

\section{Exclusion criteria:}

1- Children with any other medical or mental conditions.

2- Children with fractured anterior teeth due to caries.

3- Children whose' parents refused to sign the consent form to be included in the study.

The researcher conducted both the interview and the clinical examination.

\section{The questionnaire}

The questionnaire used in the current study includes data for age, gender, cause, time, and place of injury (Figure 1).

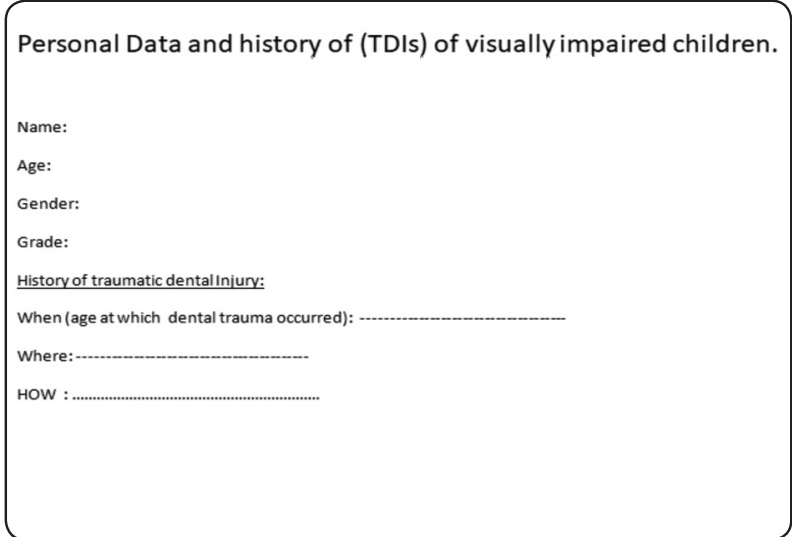

Fig. (1) The questionnaire used in the current study

\section{Clinical examination for traumatic injuries}

The clinical examination was carried out in the daylight while the children seated on a chair. Infection control measures were followed. Adequate number of disposable diagnostic kits and autoclavable community periodontal index probe were used in each day of the examination. All the children included in the study were examined 


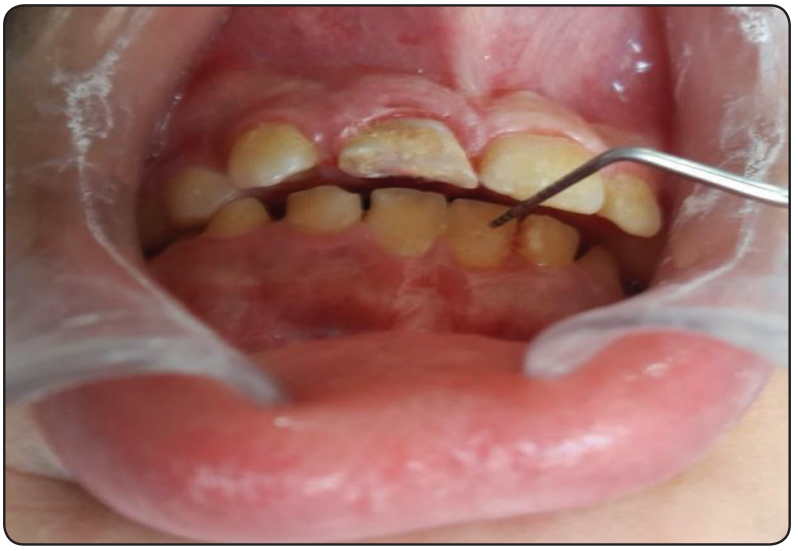

Fig. (2) Increased overjet $>3 \mathrm{~mm}$.

for the measurement of incisor overjet using the periodontal probe (Figure 2). Overjet was measured from the palatal-incisal line angle of the most prominent maxillary incisor to the labial aspect of the corresponding mandibular incisor. Overjet was recorded as increased if it is more than $3.0 \mathrm{~mm}$. Lip coverage was considered adequate when the lips covered the upper incisors in the rest position. If most of the incisors crowns were exposed at rest position, the lip coverage is recorded as inadequate (Figure 3) ${ }^{(26)}$.

All the maxillary and mandibular anterior permanent teeth were examined for traumatic injury. Trauma was recorded according to Ellis classification (1970) ${ }^{(27)}$.

Numbers of students with fractured anterior teeth due to trauma that have been restored were

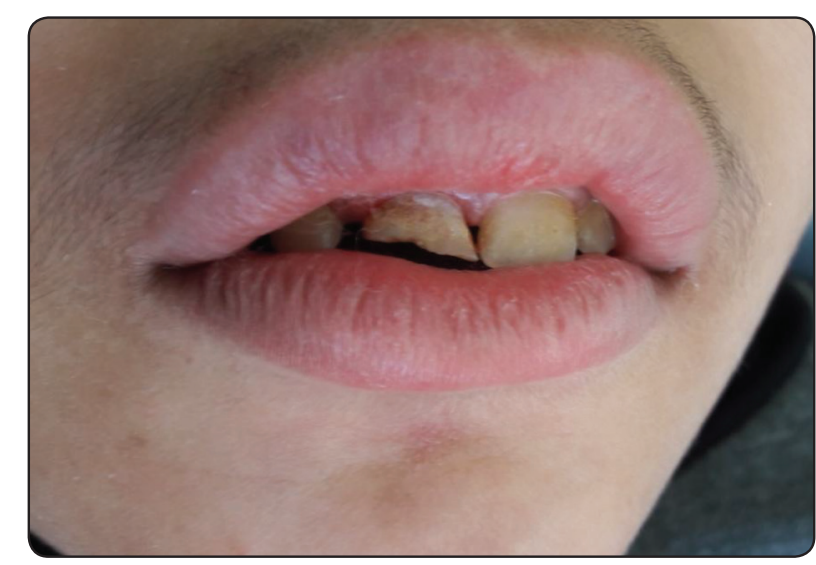

Fig. (3) Inadequate lip coverage.

also recorded.

Environmental factors at the schools represented in the degree of crowding, safety measures of the stairs and the playground areas were recorded for both schools.

\section{Statistical Analysis}

- Categorical variables were described in terms of frequency and percentage and numerical variables were described in terms of mean and, standard deviation (SD).

- Pearson's Chi-squared test was used to assess the relationship between presence of a traumatic injury with overjet and lip coverage.

- The significance level was verified at $P \leq 0.05$.

- $\mathrm{R}$ statistical package, version 3.5.2 (20-12-

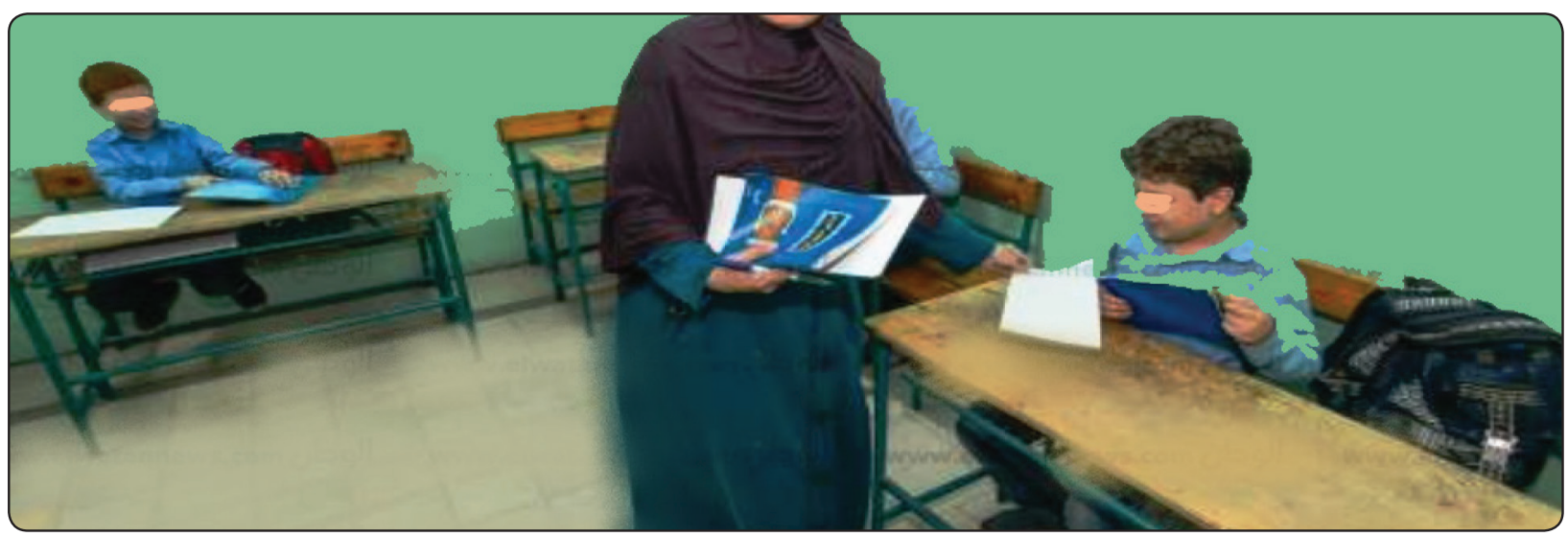

Fig. (4) students of grade 5 in the classroom. 
2018) was used in the statistical analysis of this study. Copyright (C) 2018.

[Reference: *R Core Team (2018). R: A language and environment for statistical computing. $R$ Foundation for Statistical Computing, Vienna, Austria.URL https://www.R-project.org/.]

\section{RESULTS}

In regard to the selected schools for the current study, total number of students in the boy's school was 316 students while the school for girls was 261 students.

Education for blind children needs special environment and arrangements in the classroom as well as in the playground and in the stairs. Both schools were found to have satisfactory measures in regard to the mentioned factors. Number of students per class was ranging from 8 to 12 students. Discs for the children are arranged in a unique way to avoid collision between the students (Figure 4).

Among 402 blind students examined in the current study, $210(52.2 \%)$ students were males and $192(47.8 \%)$ were females. Prevalence of traumatic dental injuries among the study population was 9.95\% (40 students). Prevalence of traumatic dental injuries among males was (11.43\%) (24 students) while it was $(8.33 \%)$ (16 students) among females (Table 1).

Table (1): Descriptive analysis for dental traumatic injuries regarding gender:

\begin{tabular}{|c|c|c|}
\hline No. of students & Without trauma & With Trauma \\
\hline $\mathrm{N}=402$ & $362(90.05 \%)$ & $40(9.95 \%)$ \\
\hline $\begin{array}{c}\text { Males } \mathrm{n}=210 \\
(52.24 \%)\end{array}$ & $186(88.57 \%)$ & $24(11.43 \%)$ \\
\hline $\begin{array}{c}\text { Females } \mathrm{n}=192 \\
(47.76 \%)\end{array}$ & $176(91.67 \%)$ & $16(8.33 \%)$ \\
\hline
\end{tabular}

Descriptive analysis regarding the different variables is shown in table 2.
TABLE (2): Descriptive analysis for Children with dental traumatic injuries regarding different variables:

\begin{tabular}{|c|c|c|}
\hline \multicolumn{2}{|c|}{ Children with trauma $n=40$} & $\mathrm{n}(\%)$ \\
\hline \multirow{8}{*}{ Tooth involved } & 7 & $3(7.5 \%)$ \\
\hline & 8 & $18(45 \%)$ \\
\hline & 9 & $11(27.5 \%)$ \\
\hline & 10 & $1(2.5 \%)$ \\
\hline & 7 and 8 & $1(2.5 \%)$ \\
\hline & 8 and 9 & $3(7.5 \%)$ \\
\hline & 7,8 and 9 & $1(2.5 \%)$ \\
\hline & 9 and 10 & $2(5 \%)$ \\
\hline \multirow{3}{*}{$\begin{array}{c}\text { Number of } \\
\text { teeth involved }\end{array}$} & 1 & $33(82.5 \%)$ \\
\hline & 2 & $6(15 \%)$ \\
\hline & 3 & $1(2.5 \%)$ \\
\hline \multirow{5}{*}{$\begin{array}{l}\text { Type of injury } \\
\text { according } \\
\text { to Ellis } \\
\text { classification }\end{array}$} & Ellis class I- Enamel fracture & $6(15 \%)$ \\
\hline & $\begin{array}{c}\text { Ellis Class II- Enamel and } \\
\text { dentine fracture }\end{array}$ & $23(57.5 \%)$ \\
\hline & $\begin{array}{l}\text { Ellis class III- Enamel and } \\
\text { dentine fracture with pulp } \\
\text { exposure }\end{array}$ & $3(7.5 \%)$ \\
\hline & $\begin{array}{l}\text { Ellis class VI- A tooth } \\
\text { devitalized by trauma with } \\
\text { or without loss of tooth } \\
\text { structure. }\end{array}$ & $2(5 \%)$ \\
\hline & $\begin{array}{c}\text { Ellis class } V \text { - Teeth lost as a } \\
\text { result of trauma. }\end{array}$ & $1(2.5 \%)$ \\
\hline \begin{tabular}{|l|}
$\begin{array}{l}\text { Fracture and } \\
\text { restoration }\end{array}$ \\
\end{tabular} & & $5(12.5 \%)$ \\
\hline \multirow{4}{*}{ Cause of injury } & Falls & $22(55 \%)$ \\
\hline & Collisions & $15(37.5 \%)$ \\
\hline & Violence & $2(5 \%)$ \\
\hline & Road traffic accidents & $1(2.5 \%)$ \\
\hline \multirow{4}{*}{ Place of injury } & Home & $22(55 \%)$ \\
\hline & Street & $8(20 \%)$ \\
\hline & School & $10(25 \%)$ \\
\hline & \multicolumn{2}{|l|}{ Mean $( \pm$ SD $)$} \\
\hline $\begin{array}{c}\text { Age at time of } \\
\text { trauma }\end{array}$ & \multicolumn{2}{|l|}{$11.85( \pm 1.47)$} \\
\hline
\end{tabular}

- Tooth involved: Upper right central incisor has the highest frequency of trauma with a proportion of $45 \%$, followed by the upper left central incisor with a proportion of $27.5 \%$.

- Number of teeth involved: $82.5 \%$ (33 children) with trauma have one injured tooth. 
TABLE (3): Comparison between children with and without traumatic injuries regarding gender distribution, Overjet and Lip coverage:

\begin{tabular}{|c|c|c|c|c|}
\hline & & $\begin{array}{c}\text { Children without Traumatic } \\
\text { injury } n=362 \\
\end{array}$ & $\begin{array}{c}\text { Children with Traumatic } \\
\text { injury } n=40\end{array}$ & $\begin{array}{c}\text { Pearson's Chi-squared } \\
\text { test } \\
\end{array}$ \\
\hline & & n $(\%)$ & n $(\%)$ & p-value* \\
\hline & Males & $186(51.38 \%)$ & $24(60 \%)$ & \\
\hline Geriuer & Females & $176(48.62 \%)$ & $16(40 \%)$ & 0.500 \\
\hline & Normal & $347(95.86 \%)$ & $22(55 \%)$ & \\
\hline Oreijet & Increased & $15(4.14 \%)$ & $18(45 \%)$ & $<0.0001$ \\
\hline & Adequate & $350(96.69 \%)$ & $25(62.5 \%)$ & \\
\hline Hip Coverage & Inadequate & $12(3.31 \%)$ & $15(37.5 \%)$ & $<0.0001$ \\
\hline
\end{tabular}

*Significance level at p-value $\leq 0.05$.

- Type of injury: Class II Ellis classification, Enamel and dentine fracture was the most common type of injury in $57.5 \%$ of the children (23 children), Six children (15\%) have class I Ellis classification, Enamel fracture, three children (7.5\%) have Class III Ellis classification, Enamel and dentine fracture with pulp exposure, while two children (5\%) have class IV Ellis classification, A tooth devitalized by trauma. Only one child $(2.5 \%)$ has class $\mathrm{V}$ Ellis classification, Teeth lost as a result of trauma.

- Five children $(12.5 \%)$ have restorations of fractured teeth due to trauma.

- Cause of injury: Falls is the most common cause of injury in 55\% (22 children), followed by collisions in $37.5 \%$ ( 15 children).

- Place of injury: Home is the most common place of injury in 55\% (22 children), street was the place TDIS in 8 children, $(20 \%)$ while in 10 children $(25 \%)$ TDIs occurred at schools.

- Age at the time of injury: Mean age of children at time of injury is $11.85( \pm 1.47)$ years.

Universal Tooth Numbering system of permanent

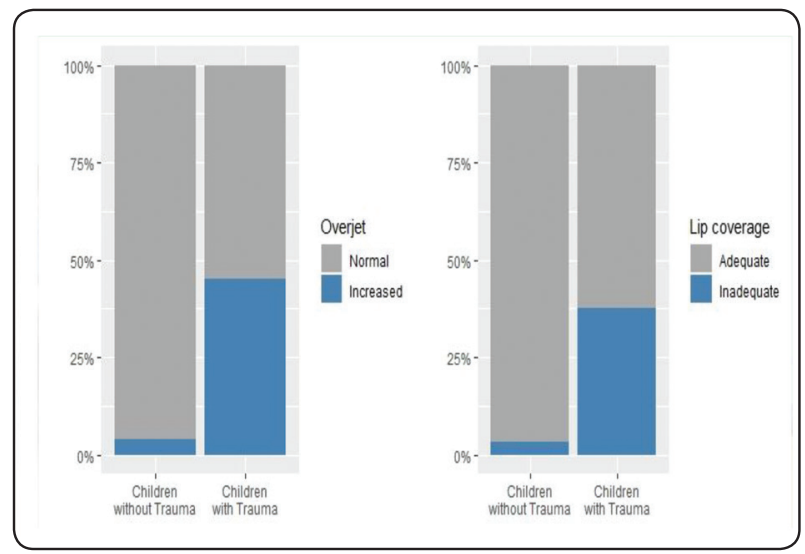

Fig. (5) Correlations between overjet and Lip coverage with traumatic injuries

dentition was used in the recording, starting from 1 to 32 .

Correlations between gender distribution, Overjet and Lip coverage with traumatic injuries are shown in table 3 and Figure 5.

- Gender: $51.38 \%$ of children without trauma are males and $48.62 \%$ are females; while in children with trauma, $60 \%$ are males and $40 \%$ are females. The difference between both groups is statistically insignificant $(\mathrm{p}$-value $=0.385)$. 
- Overjet: $95.86 \%$ of children without trauma have normal Overjet And 4.14\% have increased Overjet; while in children with trauma, $55 \%$ have normal Overjet and $45 \%$ have increased Overjet. The difference between both groups is statistically significant (p-value $=<0.0001)$.

- Lip coverage: $96.69 \%$ of children without trauma have adequate lip coverage and $3.31 \%$ have inadequate lip coverage; while in children with trauma, $62.5 \%$ have adequate lip coverage and $37.5 \%$ have inadequate lip coverage. The difference between both groups is statistically significant (p-value $=<0.0001)$.

\section{DISCUSSION}

This study was carried out to address the prevalence of traumatic injuries among a group of blind Egyptian children and the relevant factors associated with these injuries,

The prevalence of traumatic injuries among the study population was $9.95 \%$. This is close to the prevalence in Saudi Arabia 9\% ${ }^{(14)}$, but less than the prevalence in Brazil $23.1 \%{ }^{(28)}$ and in Kuwait $24.6 \%{ }^{(29)}$ and much less than the prevalence in India $32.5 \%{ }^{(30)}$.

Low prevalence is explained by the presence of strict rules for safety during the school time which in case of the male children, cover most of the week time being enrolled in a boarding school and also due to the limited activities of the blind children.

The slight increase in the prevalence of traumatic dental injuries in males compared to females is expected due to the difference in the activities of the two genders. However this difference was not significant in agreement with the results of previous studies in other countries (14, 24, 29, and 31). While some studies showed significant increase in the prevalence of dental traumatic injuries among males than females ${ }^{(1,24)}$.

As the results showed that most of the injuries occurred at home 55\% and streets $20 \%$ this might explain the insignificant difference in traumatic injuries prevalence as the male children are kept at school most of the time.

Most of TDIs affect the central incisors .There were significant correlations between increased overjet and/or inadequate lip coverage and prevalence of TDIs. This is in agreement of all the studies which correlate the prevalence of TDIs and the degree of overjet and lip coverage ${ }^{(1,14,16,22-25)}$.

Falling and collision were the most reasons for traumatic injuries, this was logic as blind children are more liable to fall and crash against different objects than being involved in violent activities. These results were in agreement with the results of Agrawal et al ${ }^{(22)}$ Munot et al ${ }^{(24)}$.

The mean age at the time of trauma was 11.8 years; this may be due to increased activities of the children at this age with lack of complete muscle coordination and self care awareness.

Enamel and dentine fracture was the most common type of fracture found in the current study followed by enamel fracture; this was in agreement with the results of other studies where enamel fracture or enamel and dentine fracture were the most common type of fracture ${ }^{(14,16,22, \text { and } 24)}$.

Lack of dental health care is obvious through the low percentage of treated TDIs where only $12.5 \%$ of the traumatized teeth were treated and restored.

\section{CONCLUSIONS}

1- Environmental factors proposed to influence the prevalence of TDIs were difficult to evaluate in the presence of similar conditions in both schools.

2- The most significant oral factors in predisposing TDIs in blind children are increased overjet and inadequate lip coverage. 


\section{RECOMMENDATIONS}

1- Dental health care for children with special needs should have a priority among governmental planes for health care. Blind children with no other physical or mental problems have the same dreams and hopes for their future as most of the sighted children.

2- More efforts should be done by health authorities to reach for those children and to introduce a better dental health service for them.

\section{REFERENCES}

1 Glendor U. Aetiology and risk factors related to traumatic dental injuries - a review of the literature . Dent Traumatol 2009; 25: 19-31.

2. Artun J, Behbehani F, Al-Jame B, Kerosuo H. Incisor trauma in an adolescent Arab population: prevalence, severity, and occlusal risk factors. Am J OrthoD dentofacial Orthop 2005;128:347-52.

3. Sgan D, Meghnagi G, Jacobi Y. Dental trauma and its association with anatomic, behavioral, and social variables among fifth and sixth grade schoolchildren in Jerusalem. Community Dent Oral Epidemiol 2005; 33:174-80.

4. Traebert J, Bittencourt DD, Peres KG, Peres MA, de Lacerda JT, Marcenes W. Aetiology and rates of treatment of traumatic dental injuries among 12-year-old school children in a town in southern Brazil. Dent Traumatol 2006; 22:173-8.

5. Soriano EP, Caldas AF Jr, Carvalho MVD, AmorimFilho HA. Prevalence and risk factors related to traumatic dental injuries in Brazilian schoolchildren. Dent Traumatol 2007; 23:232-40.

6. Oliveira LB, Marcenes W, Ardenghi TM, Sheiham A, Bo“ necker M. Traumatic dental injuries and associated factors among Brazilian preschool children. Dent Traumatol 2007; 23:76-81.

7. Hamilton FA, Hill FJ, Holloway PJ. An investigation of dento-alveolar trauma and its treatment in an adolescent population. Part 1: The prevalence and incidence of injuries and the extent and adequacy of treatment received. Br Dent J 1997; 182:91-5.

8. Marcenes W, Murray S. Changes in prevalence and treatment need for traumatic dental injuries among 14-year-old children in Newham, London: a deprived area. Community Dent Health 2002; 19:104-8.

9. Lalloo R. Risk factors for major injuries to the face and teeth. Dent Traumatol 2003;19:12-4.

10. Nicolau B, Marcenes W, Sheiham A. The relationship between traumatic dental injuries and adolescents' development along the life course. Community Dent Oral Epidemiol 2003; 31:306.

11. Nicolau B, Marcenes W, Sheiham A. Prevalence, causes and correlates of traumatic dental injuries among 13-year-olds in Brazil. Dent Traumatol 2001; 17:213-7.

12. Sabuncuoglu O, Taser H, Berkem M. Relationship between traumatic dental injuries and attention-deficit/ hyperactivity disorder in children and adolescents: proposal of an explanatory model. Dent Traumatol 2005;21:249-53.

13. Snyder JR, Knoops JJ, Jordan WA. Dental problems of non institutionalized mentally retarded children. NorthWest Dent 1960; 39:123-33.

14. Alsarheed M, Bedi R, Hunt NP. Traumatised permanent teeth in 11-16-year-old Saudi Arabian children with a sensory impairment attending special schools. Dent Traumatol 2003; 19:123-5.

15. https://www.who.int/classifications/icd/en/

16. Poureslami H, Nazarian M, Horri A, Sharifi H, Barghi H. Comparison of traumatic dental injuries between visually impaired and their peer sighted children in Kerman, Iran. J Oral Health Oral Epidemiol 2013; 2(2): 75-80.

17. The World Health Organization. Strategies for the prevention of blindness in national programmes: a primary health care approach. Geneva: the World Health Organization, 1984.

18- Said M, Goldstein H, Korra A, El-Kashlan K. Visual acuity asrelated to causes of blindness, age and sex, in urban and rural Egyptians. Am J Pub Hlth 1961: 2433-88.

19. CourtrightP, SheppardJ , SchachterJ, SaidM E and Dawson C R. Trachoma and blindness in the Nile Delta: current patterns and projections for the future in the ruralEgyptian population. British Journal of Ophthalmology, 1989, 73, 536-540.

20. Mousa A, Courtright P, Kazanjian A, Bassett K. Prevalence of visual impairment and blindness in upper egypt: A gender-based perspective. Ophthalmic Epidemiol. 2014; 21(3):190- 196. 
21. AlBajjali T, Rajab L. Traumatic dental injuries among12 year old Jordanian school children: An investigation on obesity and other risk factors. BMC Oral Health 2014; 14:101.

22. Agrawal A, Bhatt N, Chaudhary H, Singh K, Mishra P, Asawa K. Prevalence of anterior teeth fracture among visually impaired individuals, India. Indian J Dent Res. 2014; 24(6):664.

23. Ramaiah SD, Mariah PK. Prevalence of Traumatic Dental Injuries among Blind School Children in South Karnataka. IOSR J Dent Med Sci 2014;13(11):18-22.

24. Munot H, Avinash A, Kashyap,Baranwal R, Kumar B, Sagar MK. Prevalence of traumatic dental injuries among visually impaired children attending special schools of Chhattisgarh. J Indian Soc Pedod Prev Dent 2017;35:209-15.

25. Norein E, Abu Affan A. Oral Health Status, Traumatic Dental Injuries and Malocclusion among a Sample of Sudanese Visually Impaired Individuals. Indian J Dent Educ. 2016; 8(4):185-9.

26. Burden D. An investigation of the association between overjet size, lip coverage, and traumatic injury to maxillary
incisors.Eur J Orthod. 1995;17:513-517.

27. Ellis R, Davy K. The classification and treatment of injuries to the teeth of children. 5th ed. Chicago: Yearbook Medical Publishers; 1970.

28. Ferreira M, Guare R, Prokopowich I, Santos M . prevalence of dental trauma in individuals with special needs. Dental Taraumatol 2011; 27(2)113-116.

29. Shyama M, Al-Mutawa S, Honkala S: malocclusion and traumatic injuries in disabled school children and adolescents in Kuwait . Spec Care Dentist 2001, 21 (3) : 104-108.

30. Bhatt N, Agrawal A, Nagarajappa R, Roy S, Singh K, Chaudhary H, Asawa K. tooth fracture among visually impaired and sighted children of 12 and 15 years age groups of Udaipur city, India-a comparative study, Dental Taraumatol 2011; 27(5): 389-392.

31. Murthy A. Chandrakala B, Pramila M, Ranganath S. Dental trauma in children with disabilities in India: A comparative study. European Archives of Pediatrics Dentistry.2013:14; 4; 221-225. 